Title: Audience design in the police interview: the interactional and judicial consequences of audience orientation

Author's name: Dr Kate Haworth

Affiliation: Aston University, UK

Mailing address:

Dr K Haworth

Aston University

School of Languages and Social Sciences

Aston Triangle

Birmingham

B4 7ET

Email: k.haworth@aston.ac.uk

Abstract:

Police-suspect interviews in England \& Wales are a multi-audience, multi-purpose, transcontextual mode of discourse. They are conducted as part of the initial investigation into a crime, but are subsequently recontextualised through the judicial process, ultimately being presented in court as evidence against the interviewee. The communicative challenges posed by multiple future audiences are investigated by applying Bell's (1984) audience design model to the police interview, and the resulting "poor fit' demonstrates why this context is discursively counter-intuitive to participants. Further, data analysis indicates that interviewer and interviewee, although ostensibly addressing each other, may orientate to different audiences, with potentially serious consequences.

As well as providing new insight into police-suspect interview interaction, this article seeks to extend understanding of the influence of audience on interaction at the discourse level, and to 
contribute to the development of theoretical models for contexts with multiple or asynchronous audiences.

Keywords: Audience design; audience orientation; police interviews; forensic linguistics 


\section{Audience design in the police interview: the interactional and judicial consequences of audience orientation}

\section{Introduction}

Police interviews with suspects are a unique and fascinating mode of discourse, with a vitally important role in the England \& Wales $(\mathrm{E} \& W)$ criminal justice system. Interviews are conducted as part of the initial information-gathering phase of a police investigation. The resulting data then become evidence. As they subsequently pass through the criminal justice system, interview data are transformed into different formats and have several different functions for a variety of users, from the investigating police officers, to the Crown Prosecution Service (CPS), to the lawyers, judge and jury (or magistrates) of the courtroom. Interview data are thus of central importance to the judicial process, yet the effect on the data of these different audiences, the variety of purposes and the different formats has not yet been fully investigated. There are in fact some real causes for concern, both in aspects of the interaction in the interview room, and in the subsequent treatment of interview material. Haworth (2010) summarises the key issues, and elsewhere I specifically address problems with the format changes undergone by interview data (Haworth, forthcoming). This article will concentrate on the influence of the various audiences for police interviews on the interaction itself. It will be shown that there is a significant difference between interviewer and interviewee in their orientation to these future audiences and purposes, causing miscommunication in the interview room and leading to potentially serious consequences, especially for the interviewee.

The starting point for this discussion is very straightforward: who you are talking to affects what you say. Indeed Sacks, Schegloff and Jefferson (1974) describe "recipient design" as "perhaps the most general principle which particularizes conversational interactions" (727). The problem 
in the police interview context is that there are several different recipients of the discourse, and all with different purposes, from those present in the interview room to the end users in the courtroom who must ultimately decide the interviewee's fate. This is represented in Figure 1.

[Figure 1 here]

After the interview has concluded, the content will be examined by others involved in the initial police investigation, and a file will be passed to the Crown Prosecution Service who are responsible for the decision as to whether or not to formally charge the interviewee. If the interviewee is charged, their legal adviser will be given a copy of the interview as part of the package of evidence against their client. At this point the interviewee can plead guilty, in which case the process moves to the sentencing stage; or alternatively they can plead not guilty and the matter will go to trial. The interview now becomes part of the trial evidence against the interviewee, and as such will be scrutinised by lawyers representing both sides and, most significantly, by the courtroom decision-makers. (In the Crown Court the verdict is decided by a jury while a Judge oversees proceedings and determines the sentence, whereas in the lower Magistrates' Courts these roles are all performed by magistrates.)

This illustrates the complexity of the configuration of audiences for police interview discourse. In addition, most of these audiences are "hidden", in that they are not immediately present in the initial context. With regard to the different purposes, two points are immediately clear: firstly, they are rather more varied than is generally acknowledged; and secondly, these subsequent uses for interview data are of enormous importance. 
The purpose of this study is to identify the influence of these different audiences on the discourse itself, and to consider the consequences both for the initial interaction and for its use as evidence. This will be achieved by applying the model of "audience design" proposed by Bell (1984) to the police interview context. It will be seen that the interactive situation created by the configuration of audiences in this context in fact presents rather unique discursive difficulties for participants.

\section{Research background}

The effect of the intended recipient (most commonly an interlocutor) on speaker style has long been of interest in the field of sociolinguistics. In early studies audience was generally viewed as just one of several factors influencing speaker style, alongside for example the topic, setting or genre (e.g. Hymes 1974). A shift towards the centrality of audience occurred with Giles and Powesland's influential "accommodation theory" of style variation (1975), and following on from this, Bell (1984) placed audience as the primary factor in style variation, arguing that all other factors are essentially subordinate to it. He proposes a model of "audience design" which accounts for the existence of various categories of audience, from the more obvious direct addressee to overhearers and eavesdroppers, with the influence over the speaker diminishing in what is described as a fairly straightforward correlation with distance from the speaker. Although intended to account for features of stylistic variation at the level of "micro" variables as opposed to discourse level features, this model is clearly of great interest for the present study, and it will form the basis of our investigation into this factor.

Bell in fact later revisited this model, but his chief refinement regarded the concept of "referee design" (Bell 2001: 162-6), which in his own words was "an add-on" in the original model (2001: 165) but which he reconceptualised as being of more central importance. "Referees" are 
"third persons not usually present at an interaction but possessing such salience for a speaker that they influence style even in their absence" (Bell 2001: 147). This concept is thus potentially also of interest for present purposes. It is noteworthy that in revisiting the model Bell focused on looking beyond the most obvious, present audience for talk and examining other influences, yet still within the overall framework of audience design as the central guiding principle. However, for Bell "referees" are an entirely different category to "audiences"; they have no role in the interaction under consideration, and instead are a form of non-specific reference group, typefied as a speaker's "ingroup" or "an outgroup with which they wish to identify" (2001: 147). This clearly does not apply to the specific audiences identified for police interview discourse, who are, I contend, actual recipients of the talk. Thus, although this is certainly a useful extension to the original model, it does not affect the elements of audience design which will be drawn on in this particular study.

Bell's categorisation of audience roles in fact relates closely to similar categories of hearers identified by Goffman in his development of the concept of "footing" (1981: 131ff.). He proposes a "participation framework" for any instance of spoken interaction, by which a hearer's position is allocated according to their relation to a given utterance (e.g. “addressed/unaddressed”, “bystander”, “eavesdropper”). However, although this represented a significant advance in problematising the role of the hearer, it focuses on the individual's involvement in the interaction taking place, rather than their effect on the discourse they witness. It is also, as he acknowledges, restricted "to something akin to ordinary conversation" (137). He differentiates this from "stage events" such as political addresses or lectures, which have what he describes as an "audience" as opposed to "a set of fellow conversationalists" (137), and further identifies "still more difficult cases" where "neither a stage event with its audience, nor a conversation with its participants, is taking place. Rather, something binding is: court trials, 6 
auctions, briefing sessions, and course lectures are examples" (139-40). However, although Goffman's notion of footing has received considerable attention and application regarding the role of speakers (e.g. Heydon 2005 in the police interview context), far less interest has been shown in the roles of hearers.

\section{Audience and police interviews}

As already outlined, since police interview discourse recurs in multiple contexts, it therefore has multiple sets of recipients. Yet the way in which participants negotiate this unusual discursive situation has, as yet, received little academic attention. (For consideration of the transcontextual nature of police interview discourse, albeit without consideration of the influence directly on the discourse itself, see Aronsson 1991 and Komter 2002; for consideration of courtroom recontextualisation of earlier utterances from a non-interview context see Andrus 2011.) An exception is Coulthard (1996, 2002), who brings in audience as a factor in the now obsolete practice of compiling an official police interview record from the interviewers' handwritten notes. He observes that these records:

"... are, on the one hand, factual records of interaction, but on the other texts whose function is to represent this interaction at a later time to a different audience for a different purpose. ... Indeed, the police participants were certainly aware, at the time of the primary interaction, that the record was intended for, and therefore could be specifically designed for, another audience - and certainly some of these records appear to be consciously constructed with the future audience in mind.” (2002: 20)

Coulthard's observations indicate the interviewers' orientation to subsequent audiences as vitally important recipients of their written records of police interviews. However, this aspect is not the 
subject of any extended scrutiny, and the corresponding features of the original discourse could not be considered since it was not recorded at the time of the interviews concerned.

In a more recent study which does focus on interview room interaction, Stokoe and Edwards (2008) examine the asking of "silly questions" by police interviewers (e.g. "did Melvin give you permission to throw the hammer at his front door?": 90), which they demonstrate to be directed towards establishing relevant evidence against the interviewee "on record". Their analysis reveals how such questions are an important feature of the police interview context, especially in terms of fulfilling its institutional purpose, but can also represent a source of potential danger for interviewees, who do not necessarily recognise the institutional significance of their responses. They also identify that part of the difficulty that such questions pose for participants is that "asking questions with obvious answers may risk breaching the mundane norms of recipient design" (100). However, although it is implicit that the talk is directed not towards the participants, but more to the future audiences who will use the interview data as evidence, this aspect is not directly addressed.

Thus, although several studies of the police interview context have implicitly acknowledged the influence of the future audiences over the interaction itself, the nature and extent of this influence has yet to be systematically examined.

\section{Broadcast interviews}

Although the police interview context is certainly unusual in terms of the configuration of its audiences, parallels with other contexts do exist, most notably broadcast interviews. There, the presence of an overhearing, non-present and often temporally remote audience is an essential feature of the context, and hence has been the focus of some research. 
It has been shown that in that context the overhearing audience is by far the most influential in discursive terms. Greatbatch (1988) notes that "British news interview talk is designed to be hearable as being expressly produced for the consumption of a broadcast audience" (423). Clayman and Heritage (2002), building on Heritage (1985), identify "the production of talk that is targeted for an overhearing audience" as one of "two major professional tasks of broadcast journalists" (119), the other being the maintenance of a neutral stance. News interviewers thus use discursive strategies which position them not as the primary recipients of the interviewee's talk, but as "conduits" to the overhearing audience who are the real intended target for the interviewee's talk. Heritage (1985) observes that, through these discursive strategies, "questioners decline the role of report recipient while maintaining the role of report elicitor. This footing ... permits overhearers to view themselves as the primary, if unaddressed, recipients of the talk that emerges" (100).

However, although there is some similarity between broadcast and police interviews in terms of their audiences, there is a further level of complexity in the police interview context, and several key differences. Firstly, Heritage observes of the news interviewer that their "task is to avoid adopting the position of the primary addressee of interviewee's reports" (1985: 115). But the police interviewer is an intended primary recipient: they are part of the team investigating the offence in question, and are (usually) in a position to make decisions about charging and detaining the interviewee immediately consequent to the interview (subject to the agreement of the custody officer). The interviewee thus has more than one "primary" audience, and they are situated very differently in relation to the talk - physically, temporally, and in terms of their purpose. Meanwhile the interviewer has an extremely difficult position to maintain, as both 
“conduit" and primary recipient of the interviewee's talk - stances which are effectively mutually exclusive.

The second key difference is in the ratification of the overhearing audience. Broadcast interviews exist solely for their overhearing audience and, although certain fictions are occasionally maintained in recreating the illusion of a "private chat" between interviewer and interviewee, the participants are under no illusion regarding the purpose of the interaction or the primary intended audience. It is less clear whether that can truly be said of police interview participants. Although they are of course aware that they are being recorded, the nature and purpose of those who will listen to that recording is, I suggest, by no means obvious to them.

Thus, although there are similarities between these discursive contexts in that both represent a site of difficulty in managing the needs of multiple audiences, there are additional factors in the police interview context which make it even more troublesome for participants.

\section{Summary}

Although the influence of audience has long been acknowledged on "micro" features of speaker style, it has not been the subject of specific theoretical consideration at the discourse level. Studies of contexts with multiple audiences have identified this as a factor worthy of further consideration, but it has not been addressed in any depth. Yet such contexts present the ideal opportunity to investigate the importance of audience in detail, and to provide new insight into the nature of its influence. The purpose of this article, therefore, is to contribute to this process by applying an existing theoretical model of audience design to the complexities of the police interview context. 


\section{Data}

This study draws on a corpus of over 200 police-suspect interviews conducted by five English police forces between 2000 and 2005, involving a variety of offences ranging from everyday "volume" crime to murder. (It should be noted, however, that the analytic approach taken here is very much qualitative, and is based largely on detailed case studies.) These data have been fully anonymised. In addition, data are taken from the high profile case of Dr Harold Shipman, a doctor who was convicted of murdering 15 of his patients and is suspected of murdering considerably more. This case is of particular interest for present purposes not because of the nature of the case, but because data have been made publicly available from both the interview and courtroom stages of the judicial process.

\section{Audience design and the police interview}

Bell (1984) proposes that "audience design" is the most significant factor in determining the speech style adopted by any speaker; "that persons respond mainly to other persons, that speakers take most account of hearers in designing their talk" (1984: 159). He proposes four distinct audience roles, "ordered according to whether or not they are addressed, ratified, and known" (ibid.):

"The main character in the audience is the second person, the addressee, who is known, ratified and addressed. There may also be others, third persons, present but not directly addressed. Known and ratified interlocutors in the group, I term auditors. Third parties whom the speaker knows to be there, but who are not ratified participants, are overhearers. Other parties whose presence is unknown are eavesdroppers, whether intentionally or by chance.” (1984: 159)

These are represented in Bell's "Table 3", reproduced here. 
[Bell's Table 3 here]

Bell also proposes that we "picture audience members as standing on concentric circles ... each one more distant from the speaker" (1984: 159-60), as represented in his Figure 5, also reproduced here.

[Bell's Figure 5 here]

Applying this framework to the police interview context, there are (basically) two speakers, interviewer and interviewee, and a range of audience members to allocate: others initially present in the interview room (such as legal representatives); fellow police officers, the CPS, prosecution and defence lawyers; then at the court stage either the magistrates or the judge and jury.

According to Bell, "audience roles are assigned by the speaker" (1984: 160). In the vast majority of speech situations, it would seem likely that speakers in the same situation with the same set of audience members will allocate the same roles to those audiences. But this is not necessarily the case. Although Bell does not directly address this point, his model certainly allows for the possibility that audience roles (and theoretically even the audiences) can be different for participants in the same interaction. We therefore need to consider the position of each speaker separately. Starting with the interviewee, it is proposed that Bell's Table would appear as in Table $1^{1}$.

[Table 1 here] 
The future audiences are allocated as "eavesdroppers" rather than "overhearers", as in order to be classed as an overhearer the speaker must be aware of their presence. It is proposed that police interviewees are not truly aware of the future audiences for their talk. They are fully aware that they are being recorded and therefore "overheard" (hence the allocation of a "plus" in the "known" column for overhearers), but this is not the same as knowing the identity of those who will listen to that recording (hence the brackets around the "plus").

[Table 2 here]

For interviewers, it is proposed that the table would appear as in Table 2. In contrast to interviewees, for police interviewers the future audiences are allocated as “overhearers". They belong to the same institutional system, and it is part of the interviewer's professional role to be aware of their interest in, and subsequent use for, the police interview. Further, it is proposed that this institutional significance is enough to cause police interviewers to treat those audiences as actual "addressees" of their talk. This is therefore an important distinction between the interviewer's and interviewee's position.

Turning to Bell's "concentric circles" model, which represents audience roles according to their distance from the speaker, Bell observed that "[o]ften in an interaction, the physical distance of audience members from the speaker coincides with their role distance, with addressee physically closest and eavesdropper farthest away." (1984: 159-60). However, there is an additional factor in police interview discourse which is not accounted for in this model, namely time. Bell's framework assumes (not unreasonably) simultaneous presence at the speech event. But this is not the case for most of the audiences identified for police interviews. In order to account for this, a slightly more detailed version of the diagram is proposed, where within the categories of 13 
"overhearer" and "eavesdropper" each audience is further differentiated according to their temporal distance from the speech event. (Clearly this does not apply for "addressees" and "auditors" who cannot be temporally remote from the initial speech situation.) It will be noted that this still places the audience role as the primary factor, with temporal distance a subordinate category. In other words, a temporally remote overhearer is still more salient to the speaker than an eavesdropper present at the time of the initial speech event. Figure 2 represents the "concentric rings" model for the police interviewee.

[Figure 2 here]

With the additional temporal element, those in the "eavesdroppers" category (dotted outer circles) can be differentiated into those involved at the initial investigation stage (police, CPS), followed by the case preparation stages (lawyers), and at the furthest point we have the courtroom audiences.

Bell's hypothesis is that as you move further out away from the centre, the influence of that audience on the speaker diminishes (1984: 160-1). This leads to a striking observation. The audiences appearing in the outer ring of Figure 2 are from the courtroom context. We thus see that the audiences which are, I would argue, the most significant for interviewees, in that they will ultimately decide their fate, are simultaneously the audiences which interviewees are least likely to take account of during the interview. The consequences of this mis-match could potentially be enormous.

When attempting to apply the "concentric circles" model to the police interviewer, it immediately becomes apparent that this is not a straightforward matter. In Table 2 proposed 14 
above for the police interviewer, "overhearers" (i.e. the future audiences) are also addressed. But Bell's model does not allow for an audience to be simultaneously "overhearer" $\left(3^{\text {rd }}\right.$ person, outer ring) and "addressee" ( 2 nd person, inner ring). The neat correlation between distance (physical and temporal) from the speaker, and audience role, no longer holds. The model simply does not fit.

However, Bell identifies a communicative situation which is rather similar to ours in its problematic relation to his model, namely media communication. The parallels between broadcast media and police interview discourse were discussed above. Rather than undermining his theory, Bell sees such examples as the exceptions which prove his rule:

"The complex and often conflicting web of audience roles is nowhere more evident than in mass communication ... Mass communication inverts the normal hierarchy of audience roles (Figure 5) ... Rather than invalidating the addressee-auditor-overhearer hierarchy, however, it is precisely this reordering that is the site of mass communicators' difficulties in designing their utterances." (1984: 177)

I would argue that the same applies to police interviews. We have already identified a "conflicting web of audience roles"; the next step is therefore to examine the data for evidence of consequent communicative difficulties.

First we must consider how the potentially problematic influence of our "overhearing" audiences is likely to be manifest in the data. Bell's primary focus is on "style", which he addresses through analysing quantitative sociolinguistic indicators. However, he acknowledges that "[a]s we move further out to the perimeter of the audience, the quantitative effects of interlocutors become slight or indistinguishable. But while style shift may no longer register, overhearer 
design can still be manifested in qualitative language choices such as politeness-marked pronoun selection, speech act design, and bilingual language switch" (1984: 176). He cites supporting evidence from several studies, concluding that "[o]verhearer design clearly influences a speaker's style, although it is evident at macrolevels of language rather than in the quantitative shift of microvariables" (177). In other words, if we are interested in evaluating the effect of the "overhearing" audiences identified for police interviews, it is at the "discourse" level that we are likely to find our evidence.

\section{Data analysis}

The discussion above pointed to differences between the discursive positions of police interviewer and interviewee in respect of their audience orientation. They shall therefore be considered separately, before going on to assess how this affects the interaction between them.

\section{Interviewers}

Awareness of, and orientation to, the future audiences, is part of police interviewers' institutional function. Their professional experience and training make them fully aware of exactly who will subsequently listen to their talk, and their reasons for doing so. This section will demonstrate how this influences their discourse in the interview room. (It should be noted that at this stage all the future audiences will be included under one banner, although this is an obvious site for future refinement.)

The following is a typical example of direct address of the future audiences, supporting the proposition that these audiences are very much "present" in interview discourse:

\section{Example 1}


SOL: $\quad$ can I just have a look at that \{papers\} \{SOL: small cough\} thank you

IR: $\rightarrow \quad$ for the benefit of the tape I've handed the exhibit to (.) Mr Shipman's legal representative

(---) \{papers

$\rightarrow \quad$ Mr Shipman is now looking at the record himself.

(---) \{papers\}

thank you (.) I'll ask you again doctor (.) where's that information come from.

(Shipman IV2: 286-93 - author's own transcript)

The police interviewer (IR)'s two utterances marked here are clearly not addressed to anyone present. Despite the fact that he is responding to a request from Shipman's legal representative, and that he subsequently addresses Shipman directly, in these turns he refers to both those people in the third person. His reference to "the tape" makes it clear that he is instead describing what is going on in the interview room for anyone listening to the audio recording later on in the process. The following example illustrates the same phenomenon.

\section{Example 2}

IR: $\rightarrow$ yeah (.) okay. bear with me then while I just (.) show you the video and for the

$\rightarrow \quad$ purposes of the tape (.) it's video (.) er (.) NA1. which has been (.) er made as a working copy from the original which was AOH1. <okay.> (---) for the purposes of

$\rightarrow \quad$ the tape I'll (.) keep a running commentary of (.) what we can see. [...] right. the tape's (.) showing on the timing, (.) er round about err fifteen (.) forty nine, on the seventh of June. (-) (we) can see (.) if I get the speed right! (---) two males (-) 
entering the premises, (-) there's er larger of the two males is in the doorway, (.) other male's bending down, location of the locker, $[\ldots]$

(IV 2-26: 148-163)

At the start of this turn the interviewee (IE) is directly addressed ("while I just show you the video"), but the mention of "the tape" marks a shift in pronoun referent for IE. IR subsequently describes "what we can see", including everyone present in the interview room - necessarily including IE - and thus distinguishing them from the (absent) addressees of his talk.

In the following example another interviewer again seems to switch addressee mid-turn.

\section{Example 3}

IR1: okay (.) so, (.) you're saying on to this morning what happened this morning. (.) we're talking about (.) Saturday the 6th of January. what's happened.

(IV 1.02: 101-3)

IR1 initially refers to the relevant time as "this morning", which is a perfectly adequate term of reference for the purposes of all present in the temporal frame of the interview. But the deictic "this" only works within that frame. The additional temporal locator "Saturday the 6th of January" becomes necessary if, and only if, IR1 is addressing someone outside that frame.

The following is a slightly different example. Here the interviewer addresses the interviewee directly in terms of personal reference, but not in terms of the semantic content of the utterance: 


\section{Example 4}

IR: $\quad \ldots$ the $<$ scene of burglary $>$ is erm, (.) a large (.) er basically children's play area, an inside play area. (.) that's near (.) er a garden centre. does

$\rightarrow \quad$ that ring any bells with you. (.) okay you're shaking your head.

IE: $\quad($ yeah $)=$

IR: $\rightarrow \quad=$ for a no. okay mate. ...

(IV 2.26: 61-5)

IR is clearly not describing his actions for IE's own benefit: he knows he is shaking his own head! Such examples are common in the data, and can be classed as indirect address of the future audiences.

It is worth considering the extent to which the purpose of such utterances is made clear to interviewees. The following examples illustrate that interviewers are not always helpful in this respect.

\section{Example 5}

IR1: okay just describe yourself for me. what sort of build are you and size.

(IV 1.02: 253)

Here, IR1 himself clearly does not need a verbal description of a person sitting right in front of him. Once again, this information is only necessary for recipients who are not present at the interview. However, it can also be seen that IR1 specifically asks IE to provide this information for "me". This explicitly encourages IE to orientate to IR alone as his audience, when precisely 
the point of the question is to elicit information for a different audience. The following is a further example of this.

\section{Example 6}

IR: $\rightarrow$ now I called you James, e- do you p- are you happy being called James or do you (-)

IE: $\quad$ any. i[t-] it don't really matter.=

IR: [no] =yeah okay so (.) you're happy with

$\rightarrow \quad[$ James $]$ not Tommo

IE: [yeah] yep.

IR: okay mate. \{clears throat\} right. (-) let me introduce myself, my name's

John David Green, Detective Constable 123. and I'm stationed at

$\rightarrow \quad$ Midtown in the CID department. can you give me your name,=

(IV 5.11.2/1)

Here IR repeatedly addresses IE by name, displaying knowledge of both his first and surnames (the surname by implication from the abbreviated form). Indeed IE's name is the topic of discussion for several turns. Yet immediately after this, IR asks IE to give him his name. It is clear that IR does not need this information himself, and hence that it is being elicited for the purposes of other audiences for this talk. Yet IR specifically identifies himself ("me") as the primary recipient.

In fact in the immediately following talk IR does make reference to the future audiences, although he uses the vague generic noun "people" as opposed to giving any explanation of their identity or purpose: 


\section{Example 7}

IR: $\quad$... can you give me your name,=

IE: =it's James Steven Thompson.

IR: $\quad$ and date of birth,

IE: $\rightarrow \quad$ tenth of the sixth ninet[een- (??)]

IR: $\rightarrow \quad$ [and where] do you live.

IE: $\quad$ er $\{$ gives address $\}$.

IR: $\rightarrow$ right sorry give us your date of birth again,

IE: tenth of the sixth nineteen eighty

IR: right. (.) James. can I just ask you, y- you're putting your hand [over your mouth] and it muffles it up.

IE: [oh sorry. heh! \{laughs $\}]$

IR: $\rightarrow$ and [people have got to listen to this (after)].

IE: $\quad[\mathrm{er},($.$) nineteen] eighty.$

IR: right.

As requested, IE gives his date of birth, but IR begins his next question before he has completed his answer. As with IE's name, IR will already know this date as it will be written down in front of him, and hence he appears not to actually listen to the response, displaying the fact that this information is irrelevant to him personally. But his interruption of the response has thwarted his real purpose in asking the question, namely to elicit this information audibly for the future audiences and for its evidential value. He therefore goes back and repairs this. It is interesting that IR pins the blame for this lack of clarity on IE, when in fact IE's utterances are perfectly audible on the tape - it is only IR's interruption which makes it unclear. 
The future audiences thus have a discernible presence in interview room interaction, exerting a direct influence on interviewers' discourse. Some of the examples we have seen so far may seem fairly innocuous. It seems obvious from our perspective that these are for the benefit of an absent audience, and it is easy to assume that interviewees are also fully aware of this. However, as we shall see later, interviewees are apparently not always conscious of their presence as they speak.

There is one further point to note about these examples. These features could be regarded as showing interviewers orientating to the taped/audio format - in other words, adapting simply to the fact that they are being recorded. But spoken data are recorded in all manner of different contexts, yet these features seem to be strongly associated only with the police interview context. I would argue that it is too simplistic to say merely that interviewers address such utterances to "the tape". It goes well beyond that. It is not the fact that they are being recorded that matters, it is the fact that they will be listened to, and who by, and why. It is thus the audience, not the act of recording, which has an influence. This may seem to be the same basic point, but it involves a very important shift in emphasis. And it has very different consequences for the interaction precisely because of the consequences of this interaction, namely its use as evidence.

This is particularly apparent in the context of the introduction of exhibits, as in the following example:

Example 8

IR: I'm now showing you I'll put it in the middle of the room 'cause your solicitor can examine it as well then, (-) it's the exhibit JFA42. (-) and it's an insertion. (.) behind (.) your computer there's a ghost image (.) ... 
(Shipman IV2: 274-6)

Once again we see the indirect address of the future audiences: "I'm now showing you..."; "I'll put it in the middle of the room..." - as opposed to e.g. "here". In addition we have the formal identification of the item being shown: "it's the exhibit JFA42". The description alone would be sufficient for anyone not present to understand the interaction at this point. But something more is required in this context: explicit, unambiguous identification is crucial to the evidential value of any information or response gleaned from IE in connection with this document. IR must ensure that no possible argument can be raised later by Defence counsel in court about exactly what is being discussed here.

The importance of this aspect of the discourse becomes clear when an interviewer gets it wrong. In the following example IE is being interviewed following a raid on her flat, in which quantities of drugs and related items were seized. At this point in the interview, IE has admitted that some of the exhibits belong to her, but not others. The items have just been presented to her in a number of different (and individually labelled) exhibit bags.

\section{Example 9}

IR: $\quad$...cause it would look to me when I- a load of items [IE: $\mathrm{mm}$ ] are all in the same spot, along with the knife of which you say that you used to pre- you know, to to to do the stuff,

IE: $\quad \mathrm{mmm}$

IR: (-) that some of it's yours and some isn't, if that's the case then I can I'm I'm happy with that fact.

IE: $\quad[\mathrm{mhm}]$ 
IR: [okay?] I'm trying to clarify that fact, because, (.) you're sometimes saying it is, maybe, probably, but there's not a great deal of

$\rightarrow \quad$ clar[ity. so let's let's be clear then.]

IE: $\rightarrow \quad$ [well that that tha] like that one's there, like I don't know where that comes from.

IR: $\rightarrow \quad$ but we're not talking [about that.]

IE: $\quad$ [yeah I know] you're not. but I'm just s- like some them could of like (.) well some of them must have been in [(?)]
IR: $\rightarrow$
[fine, ] that's

in a different space. that's not an issue. but,

IE: $\rightarrow \quad$ so that that may that may be mine $\ldots$

(IV 2.30: 135-52)

So much for "let's be clear"! It is immediately apparent that the potential admission in the final line is meaningless to anyone who was not present in the interview room. IR fails to appreciate this, and the evidential point is lost. The problem here is that the deictic "that", used repeatedly here, is meaningless once the link to its point of reference is broken. Although it is possible to deduce what was probably being referred to here, that is insufficient evidence to support a conviction, as any Defence counsel would have exploited in court.

The consequences at the trial stage are illustrated very clearly in the following example. This is taken from the Shipman trial, during the introduction of an interview as evidence. The interview evidence is presented to the court by having prosecution counsel and the interviewing officer read out the transcript (see Haworth 2010). They have reached a point in the interview where 
Shipman was asked about the seating arrangement when a document was signed by witnesses in his surgery.

\section{Example 10}

POLICE WITNESS “OK. Where was Mrs. -- I know Mrs. Grundy was in the surgery, [being interviewer]: but she-----"

PROSECUTOR "She was sat -- if you're the witnesses stood there, Mrs. Grundy [being Shipman]: $\quad$ would be sat here."

Now just pause. Can you just explain to us how he was describing the configuration, who was seated where, or can you not remember?

POLICE WITNESS: I seem to recall it was close proximity, but I can't recall the configuration.

PROSECUTOR: $\quad$ Continue, please.

(Shipman Trial, Day 23 - official court transcript)

Once again, deixis ("there"; "here") misfires due to the audio-only format. This was potentially very important as it relates to the forging of Mrs Grundy's will. This forged will made out Shipman to be the sole beneficiary, sparking the investigation which ultimately led to Shipman's conviction for her murder. Briefly, what is at issue here is a document which was passed between the people present in this room at the time being discussed. A great deal depends on who had to pass what to whom, as fingerprints were subsequently found on a document which may or may not have been this one. Another important aspect is who was able to see the contents of this document from where they were sitting, as this is also disputed. The seating arrangement is therefore significant. The interviewer should have been well aware of this - it is presumably 25 
the reason for asking the question - and so should have clarified this at the time. But he failed to do so, and as a result the evidential value of Shipman's response is lost.

The examples in this section have illustrated the difficulties facing interviewers who are expected to address their talk to both the initial audience in the interview room, and the future audiences, at the same time. Or, to couch it in different terminology, it demonstrates the difficulty of being both primary recipient and conduit to another audience simultaneously. They have also shown how serious the consequences can be if interviewers fall short of accomplishing this problematic communicative task.

\section{Interviewees}

So far, we have seen that interviewers do adapt their discourse for the future audiences for the interview. However, this is still a difficult task for them to manage, leading to occasional oversights. But if this is difficult for interviewers, how do interviewees fare? Unlike interviewers, interviewees do not have professional experience and training to guide them through the police interview context. Instead they enter the process with only their general knowledge, and/or their own previous experience of the criminal justice system. Yet even the most experienced criminal will only have spent a very limited amount of time in an interview room. In terms of informing interviewees about other recipients of their talk, reliance is mainly placed on the wording of the caution, which warns that "it may harm your defence if you do not mention when questioned something which you later rely on in Court. Anything you do say may be given in evidence." (Police and Criminal Evidence Act Code C, para.10). Theoretically, then, they have been made aware of the future audiences, and uses, for their interview discourse. But is this sufficient for them to moderate their discursive behaviour in the same manner we have observed for interviewers? 
In fact, in striking contrast with interviewers' behaviour, I found no examples of direct or indirect address of future audiences by interviewees in my data. Instead, interviewees address their talk solely to the person in front of them, i.e. the interviewer.

This can be observed in Example 4 above. Here, IE's response to the question takes the form of a visual shake of the head, followed by the verbal "yeah". His answer is clearly intended to mean "no", but the part of his response which conveys this meaning is accessible only to those physically present. IE is patently not paying attention to how this will sound later on to other audiences, even when IR seems so obviously to be addressing exactly that point by describing his actions.

The following example (also discussed in Haworth 2010) displays a similar lack of orientation to the future audiences as addressees. It concerns an allegation of assaulting a police officer with intent to resist arrest, where legitimate self-defence is a plausible line of enquiry.

\section{Example 11}

IR: the officer's received injuries that amount to, (.) what we call $\mathrm{ABH}$... and I'll tell you what they are, (.) graze to the left right elbow, (.) graze to the lar- left right knees, (.) graze to the left right rear shoulder, (.) soreness, (.) at bruising below right breast and to (.) the nip of his er nobe on his- node on his er (.) on his chest. (-) okay?

IE $\rightarrow \quad$ (there) look there I've got some

IR: yeah, [(? what you $)$ s- $]$ 
IE: $\quad$ [from falling on] the floor $[(?)]$

IR:

[(I) hear] what you're saying, (.) but the

officer's saying, (.) that those (-) those (-) number of bruisings occurred, (.) whilst he was effectively arresting you. (-) and during the struggle that ensued.

IR provides thorough descriptive detail of the officer's injuries, yet IE singularly fails to provide similar evidence of his own injuries, with the referent of "some" remaining undetermined without the visual cue. (From the previous turn "graze", "bruising" or simply "injuries" are all possible referents.) His deictic invitation to "look there" can only be intended for IR, displaying once again an orientation solely to the immediately present audience for his talk. It is noticeable that, unlike earlier examples where the potentially missing information was much more innocuous, here IR does not seek clarity for the future audiences on this potentially significant information for the defence.

The following interviewee had a more helpful interlocutor, however. This is from an interview with a rape suspect, describing the behaviour of the complainant ${ }^{2}$.

\section{Example 12}

IR1: whereabouts was she touching you (in the pub).

IE: $\quad(-)$ just- it was just gentle stuff (tactile) you know arms, or whatever, but it's kind of (-) it's not like kind of like, (.) down, (-) sort of, (-) you

$\rightarrow \quad$ know (.) down there or whatever, [(but it's ?)]

IR1 $\rightarrow \quad$ [just for the] benefit of the tape you're 
$\rightarrow \quad$ indicating to your (.) genital re[gion is that (right ?)]

IE $\rightarrow \quad$ [yeah yeah (??) there yeah.]

As in the previous example, IE uses gesture and the deictic "there" to indicate part of his body, failing to take into account the needs of any non-present audience. IR1 is, however, alert to those needs and so provides the missing verbal description. But instead of repairing his utterance and adapting his response for that audience, IE simply repeats the faulty referent "there", indicating that he is still only orienting to the IR(s) as audience for his talk. In fact, as with Examples 5 and 6 above, although IR1's turn is clearly directed at the future audiences it does little to assist IE to do the same. He states that his clarification is for "the benefit of the tape", which is a rather oblique way of drawing attention to those who will actually listen to the tape. In addition, "the tape" to which he draws attention is physically present in the current temporal frame, further disguising the temporal and physical distance of the other audiences. And, as in Example 4, he continues to refer to IE in the second person ("you're", "your"), marking him as the direct recipient of his turn, despite the fact that the target for his words is clearly the future audiences.

The following is a slightly different example of what can happen when an interviewee fails to take the future audiences and their purposes into consideration. This interview relates to a burglary. Those present in the interview room are looking at closed-circuit television footage of the scene, and still photographs taken from the footage. These show a man committing the offence, and IR is alleging that it is IE.

\section{Example 13}

IR: can you (.) tell me whether or not you were involved in this offence,

IE: like I say I'm not saying anything at this time. 
IR: right,

IE: $\rightarrow \quad$ if (.) it goes to court, or (.) whatever the lawyer sees fit, (.) by looking at the evidence that you've showed me, then (.) I will decide on what to do then. (.) in court.

IR: okay.

IE: $\quad$ t- to be honest, (.) the photographs don't look that good. (.) er and, (???) show the lawyer them.

IR: right,

IE: because to me, (.) all as that shows is, (.) someone who is an average build, (.) looks to me like between brown and black hair, face you cannae make out because it's blurred, [there's] (nae) eyes, (nae) nose, [(you can] see)

IR: $\rightarrow \quad$ [okay, $] \quad$ [cause $] \quad$ because what we're doing now is arguing whether or not (-) erm (.) whether or not you feel there's enough (.) evidence (.) to get you through a court. (.) but I'm asking you a simple question, (.) which is, have you committed this offence!

IE: $\rightarrow \quad$ well like I say, (.) I'm not saying anything at this time! I'll let the lawyer decide.

IR: $\quad$ right. okay...

(IV 2.26: 251-99) 
This is a very interesting example. We know that this IE is a "regular", in that he is just out of prison and is already known to the police. He shows knowledge of the system and clear awareness of the future court context. But what he apparently fails to take into account is that those present in that future context are also an audience for his talk. He thus fails to tailor his discourse for that audience. It is IE who raises the subject of the evidence that will be presented in court. But he has completely failed to take into account that this interview is itself evidence, too. His point here is that the video evidence is not enough on its own to get a conviction. This may well have been the case. Yet I would argue that for the audience listening in court and attempting to reach a verdict, the combination of the video and IE's response to it at interview, in which he prioritises challenging the quality over issuing a straightforward denial that he was there, is now almost certainly enough. He has effectively incriminated himself. (It is worth noting that he had waived his right to legal representation.)

This example fits well with the "audience design" arrangement for interviewees proposed above (Figure 2). It illustrates how interviewees orientate almost exclusively to the audience closest to them (i.e. the interviewer), and address their talk least to the most remote audience (i.e. the court). What is particularly striking about this example is that it shows an interviewee being explicitly aware of a remote future context and audience, while simultaneously failing to consider them as an addressee. This is even more striking given that here IE also demonstrates his awareness that the court is ultimately the most important audience in the process of which this interview is part. It seems that even this is insufficient to override IE's in-built "audience design" model, whereby he sees IR as the primary - perhaps only - recipient of his talk. As clearly shown in this example, this is a potentially dangerous oversight. 
Nevertheless, it is clear that it is this IE's own actions - or rather words - that lead him into difficulty. He is the author of his own misfortune, through a failure to consider all those who will ultimately receive his talk. In the context of an investigation into a criminal offence, it may be argued that this is entirely legitimate, if one considers that a primary purpose of the interview is to establish the "truth". However, it effectively violates an important legal principle, namely the privilege against self-incrimination ${ }^{3}$.

In summary, in line with the predicted model for police interviewee "audience design" proposed above, interviewees have been shown to orientate almost exclusively to the physically present audience for their talk, namely their interviewer, and on the immediately contemporaneous context of the interview. They almost entirely fail to consider the more remote but highly significant audiences for their talk later on in the judicial process, potentially to their considerable detriment.

\section{Interviewer-interviewee (mis)communication}

So far we have examined the discursive behaviour of interviewer and interviewee independently, and observed key differences in their audience awareness and orientation. We shall now consider how this affects interaction between them.

We have seen that interviewers have a difficult professional task to manage, in that they are expected to address both their initial, physically present audience as well as attending to the wider institutional requirements of the absent future audiences. Examples 9 and 10 have shown that when an interviewer focuses on the interaction with the interviewee, the communicative link to the future audiences can be broken, and the evidential purpose frustrated. By the same token, if an interviewer focuses too heavily on directing his talk to the future audiences, communication 
in the actual interview room can become problematic. This can be seen in the following example.

\section{Example 14}

IR: $\quad$ from your records, (.) which you've had access to for some time now, (-) can you point out where the visits you made (.) to Mrs Mellor (-) are (.) indicated. (.) on them records.

IE: $\quad$ which visits are we talking about.

IR: well you said there was a visit in the morning, (.) [you then-]

$$
\text { IE: } \quad[\mathrm{nn} \text { no] I said that she }
$$

$\rightarrow \quad$ came to surgery. (.) it's here it's quite clear.

IR: $\rightarrow \quad$ can you just show me where that is.

IE $\rightarrow \quad$ hhh I thought that was perfectly clear. the $11^{\text {th }}$ of the $11^{\text {th }}$ here.

IR: $\rightarrow \quad$ so that's on page nine, (--) and it's the second entry (.) $11 / 5 / 98,($. angina pectoris. (--)

(Shipman IV2: 114-24)

In this example we see that IE fails to understand IR's apparent inability to see what he is referring to, namely the document in front of both of them. He has been asked to point out where his visits are indicated on this document, and (as far as he can see) he has done so: "it's here it's quite clear". But although this is a sufficient answer for IR personally, it is not for the overhearing audience, and so IR makes what appears to IE to be an entirely superfluous further request: "can you just show me where that is". The audible sigh suggests exasperation on the part of IE, yet the repetition of his response that the answer is "clear", and the repeated deixis ("here"), show that he has still failed to understand the underlying point of this exchange - that 
he is being asked to address the future audiences, not the present one. In the end, having failed to elicit the answer he wanted from IE, IR himself makes identification explicit: "so that's on page nine...".

We thus see that in terms of ordinary communicative principles, IR's turns here do not make sense to IE, leading to a breakdown in understanding between the participants. IR and IE are effectively addressing different audiences at the same time. IE is talking directly to IR, but IR is mainly directing his talk to the future audiences. It is therefore not surprising that this leads to miscommunication between them.

However, the situation is not entirely that simple. Straight after this exchange, IE makes a very interesting reference to the tape:

Example 14 (cont'd)

IR: $\quad$ so that's on page nine, (--) and it's the second entry (.) $11 / 5 / 98,($.$) angina$ pectoris. (--) I don't understand what these terms mean here. perhaps you could explain them for me. is this the right place I'm looking at

IE: yes that's the right place you're looking at, and I read that record out to $\rightarrow \quad$ you on the previous tape. and if you wish I'll do it again.

(Shipman IV2: 123-7)

Note that he does not say "I read that in the previous interview", as might be expected. So, paradoxically, he is clearly very aware of the fact that his words are being recorded, but is nonetheless apparently still only considering IR as the audience for that recording - as indicated through his pronoun choice here. This is a neat illustration of the point made earlier, that awareness of being recorded is not the same thing as awareness of future audiences, and that 34 
addressing talk to "the tape" is not the straightforward corollary of treating future audiences listening to that tape as addressees. This is a vital communicative distinction.

\section{Discussion}

This study has identified a complex configuration of audiences for police interview interaction. Using Bell's audience design model, we have seen that this configuration differs in significant ways from more common interactive situations, presenting unusual challenges for participants. Further, the proposed configuration suggested different audience orientation on the part of interviewer and interviewee, a hypothesis which is borne out through analysis of the data. It has been shown that interviewers do make attempts to address the future audiences during the interview, and moderate their discourse accordingly. Yet this is not an easy task to manage, and we have seen that they do occasionally slip up, seriously affecting the quality of the interview as evidence as a consequence. This is a result of their institutionally ambiguous role as both primary recipient of the interviewee's talk, and as elicitor of that talk for the future audiences. Meanwhile, we have seen that interviewees do not treat the future audiences as addressees of their talk, but instead focus purely on the immediately present audience and temporal context. This not only leads to miscommunication between participants, but can also be extremely detrimental for the interviewee's position in the wider context of the judicial process of which the interview is but one part.

Further, using our adapted version of Bell's "concentric rings" model, we have identified the court context as the most distant from the speech event physically and temporally, pushing it to the "outer rings" in terms of interviewees' orientation to it as an audience, but as simultaneously the most important audience in terms of the consequences of the interaction. It is, I would argue, 
this complete reversal of the ordinary communicative model that makes it so difficult for participants to adapt to the police interview audience configuration. Interviewers fare better due to their professional experience and training, while interviewees generally fail to account for this altogether.

Yet it was noted that at the same time as addressing their own talk to the future audiences indeed asking questions specifically for their purposes - interviewers did not encourage the interviewees to address that intended audience in their responses. In fact we observed them almost encouraging an interviewee in the opposite direction, explicitly inviting them to direct their talk to the interviewer personally (Examples 5 and 6).

This leads into a conflicting and problematic part of the interviewer's function, namely the question of neutrality. A potential role for the interviewer is that of a neutral and disinterested conduit between the interviewee and the ultimate audiences for their talk. This is akin to the role of broadcast interviewers discussed earlier. However, the analogy breaks down in that police interviewers are clearly not disinterested; they are also investigating police officers and hence part of the prosecution establishment. They are therefore by definition not neutral, despite the apparent expectations of the criminal justice system.

Yet it is clear that the interviewer's institutional - and hence discursive - position is in fact to act as a filter between interviewee and ultimate audience. However, interviewees are not made aware of this, so instead of being a transparent medium through which interviewees' talk is filtered, interviewers in fact form an opaque block between the interviewee and their audience which interviewees apparently do not see past. There is no suggestion, however, that this is a deliberately deceptive strategy on the part of police interviewers, but rather is a consequence of 36 
their conflicting discursive position. Indeed it was observed that the outcome, in terms of missing or distorted information, is potentially as damaging to the Prosecution as to the Defence. Overall, then, it is clearly in the interests of all concerned that the future audiences for police interview discourse are made considerably more manifest in the interview room than mere references to "the tape".

\section{Conclusion}

It must be emphasised that this is intended as a starting point for investigating the influence of audience orientation in the police interview, and indeed in other transcontextual data. What I hope to have demonstrated here is the potential usefulness of applying the concept of audience design to this context. The model provides a meaningful explanation for phenomena which had already been observed in police interview discourse, such as the fact that interviewers routinely provide explanations "for the tape" while interviewees do not. It seems essential to shift the focus onto the audience rather than the recording process, which is patently obvious to all participants equally. It also provides a potential framework for accounting for other discursive behaviour of participants in an observable and measurable way.

In terms of the audience design model itself, Bell (2001) in discussing potential extensions to the model noted that new explanations "may go beyond strict accommodation to the present audience, but what is very obviously going on in the situation may be the design of talk in relation to some person or group in a way that is a natural extension of the audience approach" (163-4). Bell's own extension involved expanding on the concept of "referees" as a further salient influence (165-6), but the present analysis indicates that the concept of "audience" can also be extended beyond those actually present. The future audiences for police interview 
discourse are far more well-defined and directly involved than either a referee group or a generic audience for broadcast media, and, I believe, need to be accounted for as actual recipients of interview talk. This is necessary in particular to account for the examples of direct address given above.

In terms of practical applications, the audience design model provides a clear picture of how unusual a discursive position participants find themselves in, and thus has the potential to equip them with a better understanding of the interaction in which they are involved and how to manage it successfully. Indeed an indication of this potential is that the model has been received enthusiastically by police interviewer trainers to whom I have presented these findings, and has already been incorporated into interviewer training for one regional English police force. The concept appears to be an intuitively good fit with phenomena that interviewers themselves recognise and struggle with on a daily basis. The next challenge, of course, is ensuring that interviewees are given the same benefit.

\section{References}

Andrus, Jennifer (2011). Beyond texts in context: Recontextualization and the co-production of texts and contexts in the legal discourse, excited utterance exception to hearsay. Discourse and Society 22(2): 115-136.

Aronsson, Karin (1991). Social interaction and the recycling of legal evidence. In N. Coupland, H. Giles, and J. Wiemann (eds.), “Miscommunication” and Problematic Talk, 215-243. Newbury Park: Sage. 
Bell, Allan (1984). Language style as audience design. Language in Society 13: 145-204.

Bell, Allan (2001) 'Back in style: Reworking audience design'. In P. Eckert \& J.R. Rickford (eds.), Style and Sociolinguistic Variation, 139-169. Cambridge: Cambridge University Press.

Clayman, Steven and Heritage, John (2002). The News Interview: Journalists and Public Figures on the Air. Cambridge: Cambridge University Press.

Coulthard, Malcolm (1996). The official version: Audience manipulation in police records of interviews with suspects. In C.R. Caldas-Coulthard \& M. Coulthard, Texts and Practices: Readings in Critical Discourse Analysis. London: Routledge, 166-78.

Coulthard, Malcolm (2002). Whose Voice Is It? Invented and Concealed Dialogue in Written Records of Verbal Evidence Produced by the Police. In Janet Cotterill (ed.) Language in the Legal Process, 19-34. Basingstoke: Palgrave.

Giles, H. and Powesland, P.F. (1975). Speech style and social evaluation. London: Academic Press.

Goffman, Erving (1981). Forms of Talk. Oxford: Blackwell.

Greatbatch, David (1988). A turn-taking system for British news interviews. Language in Society 17: 401-30. 
Haworth, Kate (2010). Police interviews as evidence. In Malcolm Coulthard \& Alison Johnson (eds.) The Routledge Handbook of Forensic Linguistics. Abingdon: Routledge

Heritage, John (1985). Analysing news interviews: aspects of the production of talk for an overhearing audience. In Teun A. van Dijk (ed.), Handbook of Discourse Analysis, Vol. 3, 95-117. London: Academic Press.

Heydon, Georgina (2005). The Language of Police Interviewing: A Critical Analysis. Basingstoke: Palgrave.

Hymes, Dell (1974). Foundations in Sociolinguistics: An ethnographic approach. Philadelphia: University of Pennsylvania Press.

Komter, Martha L. (2002). The Suspect's Own Words: The Treatment of Written Statements in Dutch Courtrooms. Forensic Linguistics 9(2): 168-92.

Sacks, Harvey, Schegloff, Emmanuel A., and Jefferson, Gail (1974). 'A simplest systematics for the organization of turn-taking for conversation'. Language 50(4): 696-735.

Stokoe, Elizabeth \& Edwards, Derek (2008). 'Did you have permission to smash your neighbour's door?' Silly questions and their answers in police-suspect interrogations. Discourse Studies 10(1): 89-111. 
Figure 1: Audiences and purposes for interview data

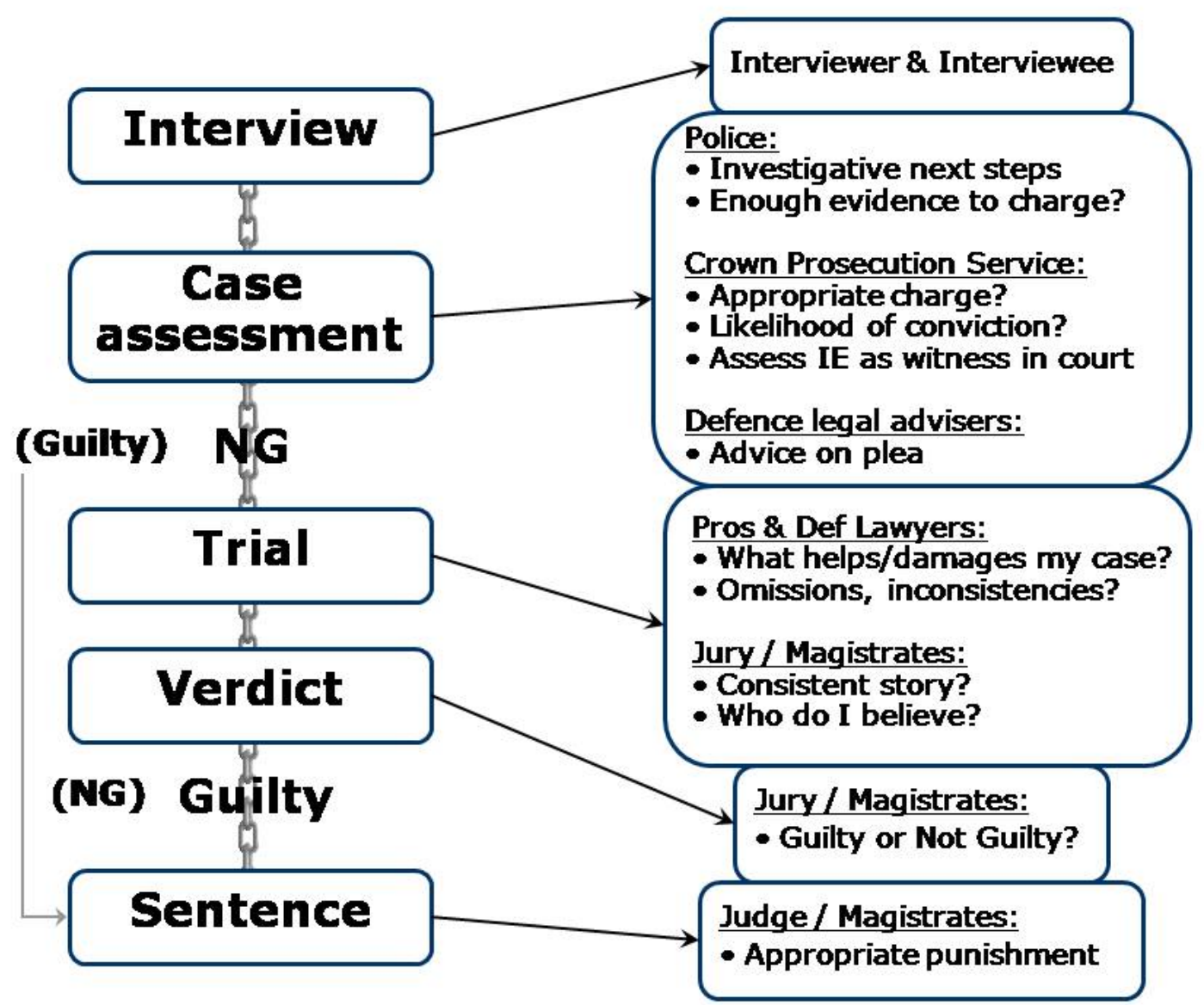


Bell's "Table 3. Hierarchy of attributes and audience roles"

\begin{tabular}{|l|l|l|l|}
\hline & Known & Ratified & Addressed \\
\hline Addressee & + & + & + \\
\hline Auditor & + & + & - \\
\hline Overhearer & + & - & - \\
\hline Eavesdropper & - & - & - \\
\hline
\end{tabular}

(Bell 1984: 160) 
Bell's "Figure 5: Persons and roles in the speech situation"

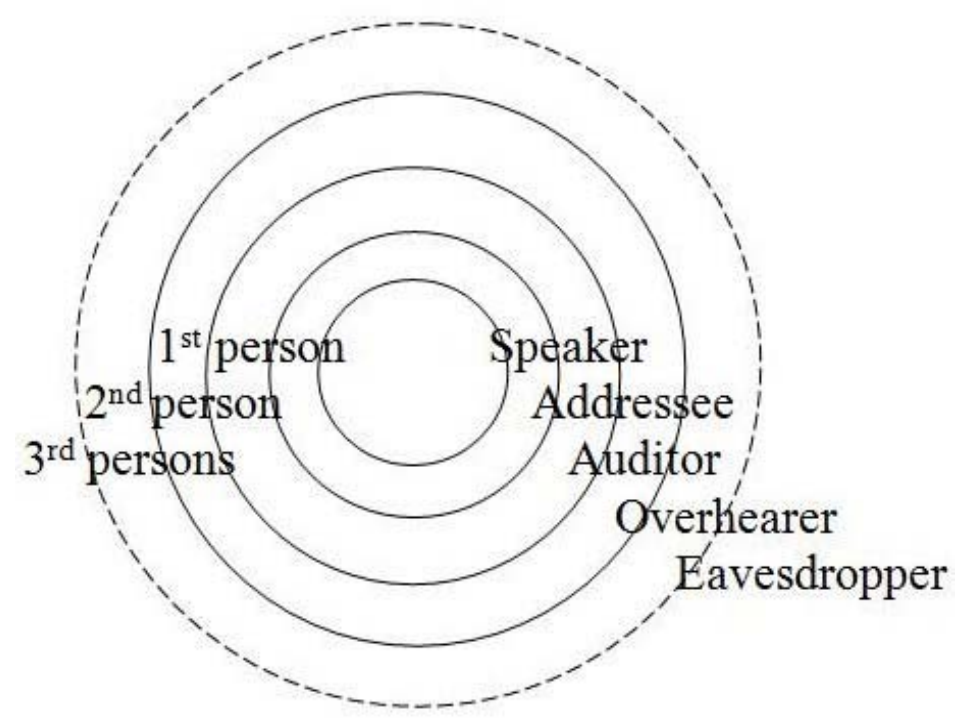

(Bell 1984:159) 
Table 1: "Hierarchy of attributes and audience roles" for interviewees

\begin{tabular}{|l|l|l|l|}
\hline & Known & Ratified & Addressed \\
\hline Addressee: Interviewer & + & + & + \\
\hline Auditor: legal representative & + & + & - \\
\hline Overhearer: - & $(+)$ & - & - \\
\hline Eavesdropper: Police, CPS, & - & - & - \\
lawyers, jury, judge, Mags. & & & \\
\hline
\end{tabular}


Table 2: "Hierarchy of attributes and audience roles" for interviewers

\begin{tabular}{|l|l|l|l|}
\hline & Known & Ratified & Addressed \\
\hline Addressee: interviewee & + & + & + \\
\hline Auditor: legal representative & + & + & - \\
\hline Overhearer: police, CPS, & + & - & + \\
lawyers, jury, judge, mags. & & & \\
\hline Eavesdropper: - & - & - & - \\
\hline
\end{tabular}


Figure 2: "Persons and roles in the speech situation" for interviewees

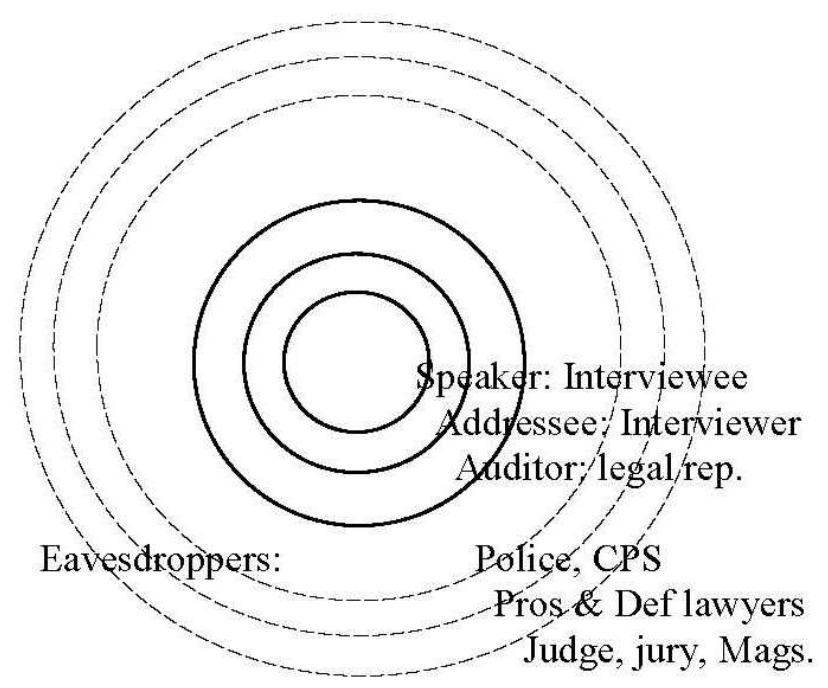

${ }^{1}$ A note of caution must be sounded regarding the treatment of legal representatives here. While their categorisation as auditors seems straightforward, their discursive role in this context is complex and inconsistent, and worthy of further study in its own right. In addition they are not present in the majority of interviews. Their position in these Tables should therefore be considered as a preliminary marker, and it is intended to return to this in future studies.

${ }^{2}$ Without wishing to over-interpret the data, it is worth observing that a rape suspect is assisted while a person accused of assaulting a police officer is not. In fact an extended analysis of the interview with the rape suspect revealed several other instances of "assistance" which have not been observed in other interviews.

${ }^{3}$ This rule means that a person cannot be compelled to give incriminating evidence against themselves. Thus a person can refuse to provide certain information or answer certain questions if this would in itself provide evidence which could lead to their conviction. Of course, people frequently waive this right without ever realising it existed. 